\title{
Water-borne pressure-sensitive adhesives acrylics modified using amorphous silica nanoparticles
}

\author{
Zbigniew Czech $^{1 *}$, Zbigniew Maciejewski ${ }^{2}$, Krystyna Kondratowicz-Maciejewska ${ }^{3}$ \\ ${ }^{1}$ West Pomeranian University of Technology, Szczecin, Faculty of Chemical Technology and Engineering, Institute \\ of Chemical Organic Technology, Pułaskiego 10, 70-322 Szczecin, Poland \\ ${ }^{2}$ Pasaco, Toruńska 63a, 86-050 Solec Kujawski, Poland \\ ${ }^{3}$ UTP University of Science and Technology, Department of Environmental Chemistry, Faculty of Agriculture and Bio- \\ technology, Seminaryjna 3, 85-326 Bydgoszcz, Poland \\ "Corresponding author: e-mail: psa_czech@wp.pl
}

\begin{abstract}
The application of water-borne pressure-sensitive adhesives (PSA) based on acrylics is increasing in a variety of industrial areas. The have been used for manufacturing of double sided and carrier free mounting tapes, splicing tapes, marking and sign films, self-adhesive labels, packaging tapes, protective films and diverse high quality medical materials. Nano-sized inorganic fillers can modify diverse adhesive and self-adhesive coating properties such as tack, peel adhesion, shear strength at $20^{\circ} \mathrm{C}$ and $70^{\circ} \mathrm{C}$, and removability Amorphous synthetic silica nanoparticles in form of water dispersions: Ludox PX-30 (30 wt.\% silica stabilizing with counter ion sodium), Ludox PT-40 (40 wt.\% silica stabilizing with counter ion sodium), Ludox PT-40AS (40 wt.\% silica stabilizing with counter ion ammonium), and Ludox PW-50 (50 wt.\% silica stabilizing with counter ion sodium) (from Grace) in concentrations between 1 and 5wt.\% were used for modifying of water-born pressure-sensitive adhesive acrylics: Acronal 052, Acronal CR 516 (both BASF) and Plextol D273 (Synthomer) properties. It has been found in this study that the nano-technologically reinforced system containing of Acronal 052 and amorphous silica Ludox PX-30 showed a great enhancement in tack, peel adhesion and shear strength. In this paper we evaluate the performance of Acronal 052 modified with amorphous silica Ludox PX-30.
\end{abstract}

Keywords: water-borne pressure-sensitive adhesives, acrylics, amorphous silica, tack, peel adhesion, shear strength.

\section{INTRODUCTION}

Modern water-borne pressure-sensitive adhesives (PSA) characterized by high-performance must often meet competing requirements in their molecular structure. For instance, they must produce a hard and firm joint in form of polymer layer, yet must at the same time cushion dangerous stress peaks. Their viscosity must be as low and constant as possible during application, but at the same time, no severe shrinkage should occur during crosslinking $^{1-5}$. Significant challenges are therefore faced in the development of new water-borne pressure-sensitive adhesives based on acrylics containing suitable nanoparticles $^{6-10}$. Nanoparticles as crystalline or amorphous silica, thousands of times smaller than the cross section of a human hair, have unique properties because of their small size ${ }^{11}$. One of their most important features is that nanoparticles are much smaller than the wavelength of light, and therefore do not scatter it, are invisible even of billions of them are presented in the material. Thus is becomes possible to produce new mechanical materials with ameliorated properties. Of particular interest for water-borne PSA is that if nanoparticles present in the adhesives are well and easy distributed, they can significant change the water-borne adhesives properties ${ }^{12}$.

Nanolayers based on water-borne acrylic pressuresensitive adhesives after drying process in drying canal have attracted attention due to their superior engineering properties compared to the neat polymer and to the classical composites ${ }^{13-17}$. Water-borne acrylic PSA containing amorphous silica in form of water dispersions have gained great interest in recent decades because of their unique properties ${ }^{18}$. Until now, no works have been reported about the using of special amorphous silica nanoparticles for modification of water-borne acrylic PSA systems in spite of the technical several advantages.

\section{EXPERIMENTAL}

Modification of commercial water-borne acrylic PSA with silica nanoparticles

For the experimental trials three commercial water-borne acrylic PSA, namely Acronal 052 and Acronal CR 516 (both products from BASF) and Plextol D273 (Sarthomer) were selected and modified with amorphous silica nanoparticles Ludox PX-30, Ludox PT-40, Ludox PT-40AS and Ludox PW-50 from Grace. All amorphous silica particles are colloidal aqueous solutions characterized by concentration of silica fillers and $\mathrm{pH}$ value.

The mechanical incorporation of amorphous silica nanoparticles into selected water-borne acrylic PSA was achieved by mixing the mentioned silica types with water-borne PSA using a dissolver at the high mixing speed of $7.000 \mathrm{rpm}$ for $15 \mathrm{~min}$. No problems with the dispergation process of silica nanoparticles were observed.

\section{Coating of modified water-borne acrylic PSA}

The modified dispersions containing amorphous silica nanoparticles are coated on $50 \mathrm{~mm}$ thick polyester film with coat weight of $25 \mathrm{~g} / \mathrm{m}^{2}$ and dried $10 \mathrm{~min}$ at $110^{\circ} \mathrm{C}$ in drying canal. The resulted self-adhesive layers are protected with silicon paper, cut in $2.5 \mathrm{~cm}$ with tapes and after 1week storage at room temperature tested according to international industrial specification on tack. 
Tack measurement of water-borne acrylic PSA containing tested silica nanoparticles

Tack of pressure-sensitive adhesives is the adhesive property related to bond formation. Generally, the test procedure to measure tack consists of two steps: bond formation and bond separation, which are to be measured at low contact pressures and short contact times. Tack method measures the instantaneous adhesion of loop of adhesive-coated material using no external pressure to secure contact. According to another definition the quick stick tack value is the force required to separate a loop of material at a specific rate, which was brought into contact with a standard surface. The tack method according to AFERA 4015 is relatively simple and may be carried out using common tensile strength test machines (Fig. 1). A sample of PSA coated material 2.5 $\mathrm{cm}$ wide and $17.5 \mathrm{~cm}$ long is bonded to a vertical clean steel test plate at least 10 lineal $\mathrm{cm}$ in firm contact. The vertical steel test plate is clamped in the jaws of a Zwick/ Roell Z1.0 tensile testing machine. The scale reading in Newtons is recorded as the tape is peeled from the steel surface with a constant rate of $100 \mathrm{~mm}$ per minute.

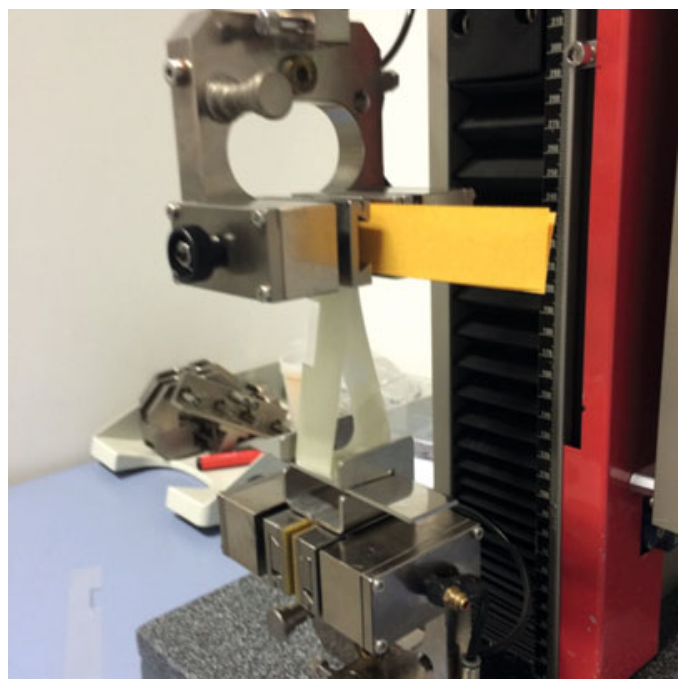

Figure 1. Evaluation of the tack of self-adhesive materials

Peel adhesion measurement of water-borne acrylic PSA containing tested silica nanoparticles

The peel adhesion is the force required to remove a coated flexible pressure-sensitive adhesive sheet material from a test panel measured at a specific angle and rate of removal. For $180^{\circ}$ peel measurements (AFERA 4001) the results depend on the face stock material. A sample of PSA coated material $2.5 \mathrm{~cm}$ wide and 12.7 $\mathrm{cm}$ long is bonded to a horizontal target substrate surface of a clean steel test plate at least $12.7 \mathrm{~cm}$ in firm contact. A $2 \mathrm{~kg}$ hard rubber roller is used to apply the strip. The free end of the coated strip is doubled back nearly touching itself so the angle of removal will be $180^{\circ}$ (Fig. 2). The free end is attached to the adhesion tester scale. The steel test plate is clamped in the jaws of a tensile testing machine Zwick/Roell Z1.0, which is capable of moving the plate away from the scale at a constant rate of $300 \mathrm{~mm}$ per minute. The scale reading in Newtons is recorded as the tape is peeled from the steel surface. The data is reported as the average of the range of numbers observed during the test. The given result is an arithmetic average from the available peel adhesion results.

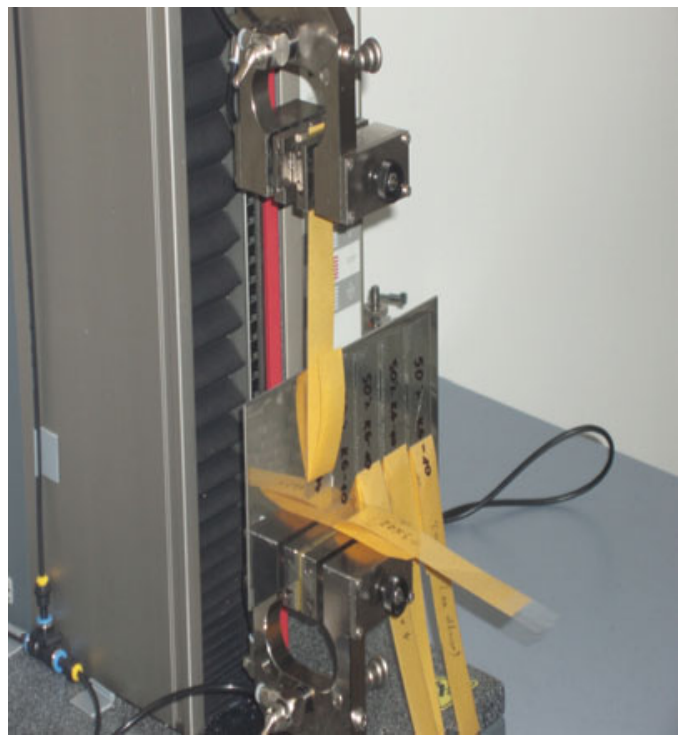

Figure 2. Evaluation of the peel adhesion of self-adhesive materials

\section{Shear strength measurement of water-borne acrylic PSA containing tested silica nanoparticles}

The shear strength is a measure of the cohesiveness or internal strength of an adhesive. It is based upon the value of force required to pull an adhesive strip from a standard flat surface in a direction parallel to the surface to which it has been affixed with a definite pressure, according to AFERA 4012 , at $20^{\circ} \mathrm{C}$ and at $70^{\circ} \mathrm{C}$. It is measured in $\mathrm{N}$ required to pull a standard area of adhesive coated sheet material from a stainless steel test panel under stress of a load between 5 and $90 \mathrm{~N}$ (tested at $20^{\circ} \mathrm{C}$ ) and between 5 and $40 \mathrm{~N}$ (tested at $70^{\circ} \mathrm{C}$ ). Static shear strength (Fig. 3 ) is the adhesive's ability to maintain its position when shearing forces are applied. Each test is conducted on an adhesive-coated strip applied to a standard stainless steel panel in a manner such that a $2.5 \mathrm{~cm} \times 2.5 \mathrm{~cm}$ portion of the strip is in fixed contact with the panel with one end of the strip being free. The steel panel with the coated strip attached is held in a rack such that the panel forms an angle of $178-180^{\circ}$ with the free end tape extended; the latter then is loaded with a force of different hanging weight in $\mathrm{g}$ or $\mathrm{kg}$ applied from the free end of the test strip. The time elapsed for each coated film to separate from the test panel was $4 \mathrm{~h}$.

\section{Removability of water-borne acrylic PSA containing tested silica nanoparticles}

PSA of the present work are considered removable if they are removed cleanly from a test substrates without causing any damage to the test substrates over a range of peel rates and varied periods of dwell at room temperature.

A strip $2.5 \mathrm{~cm}$ in width of the sheet coated with the PSA to be tested is applied to the horizontal surface of a steel and polyester test substrates with at least 12.7 $\mathrm{cm}$ in firm contact. Three passes in each direction with a $2 \mathrm{~kg}$ hard rubber roller are used to apply the strip. If air bubbles are entrapped between the test substrate and the test strip, the sample is discarded. After one day 


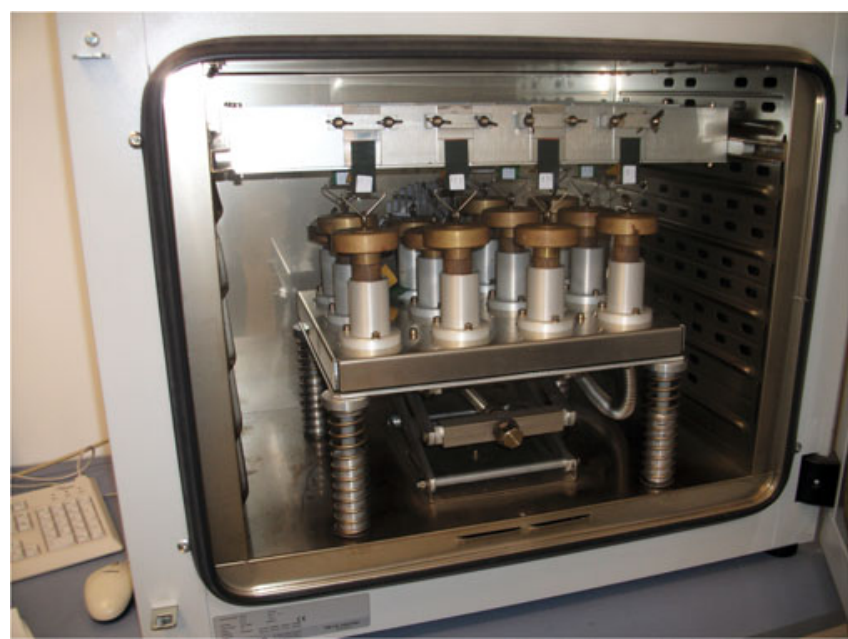

Figure 3. Evaluation of the shear strength of self-adhesive materials

and one week dwell, the free and of the coated strip is doubled back nearly touching itself so the angle of removal will be about $135^{\circ}$. The free and is then pulled by hand at a variety of peel rates.

\section{RESULTS AND DISCUSSION}

Measurement of commercial water-borne acrylic PSA properties containing silica nanoparticles

The main properties of the unmodified and containing amorphous silica nanoparticles commercial water-borne acrylic PSA such as tack, peel adhesion, shear strength and removability are shown in Table 1 and Figures 4-7.

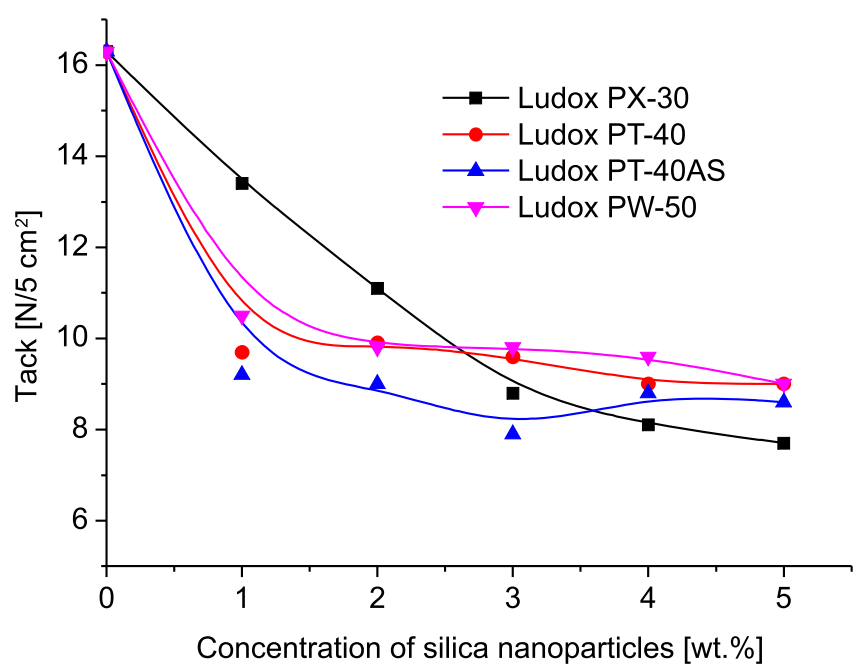

Figure 4. Tack of water-borne acrylic PSA Acronal 052 modified with silica nanoparticles

\section{Tack}

The typical dependence of tested inorganic fillers on fillers containing PSA is the increasing of tack showed in Table 2. The best results were observed for commercial dispersion Acronal 052 what was illustrated in Figure 4.

It can be concluded from these experimental results that all the tested amorphous silica nanoparticles from Grace have a negative influence on tack of water dispersion Acronal 052 although the best results are achieved for Acronal 052 modified with silica nanoparticles Ludox PX-30. The smallest reduction of tack observed for Ludox PX-30 in comparison with other investigated aqueous silica nanoparticles is retired to smallest concentration of silica nanoparticles of $30 \mathrm{wt} . \%$ in Ludox PX-30. Other aqueous silica nanoparticles contain 40 or $50 \mathrm{wt} . \%$ silica.

Table 1. Tack of investigated PSA dispersions modified with nanosilica from Grace Company

\begin{tabular}{|c|c|c|c|}
\hline \multirow{2}{*}{$\begin{array}{l}\text { Amount of silica nanoparticles } \\
\text { [wt.\%] }\end{array}$} & \multicolumn{3}{|c|}{ Tack $\left[\mathrm{N} / 5 \mathrm{~cm}^{2}\right]$} \\
\hline & Acronal 052 & Acronal CR516 & Plextol D273 \\
\hline \multicolumn{4}{|l|}{ Ludox PX-30 } \\
\hline 0 & 16.3 & 15.0 & 14.7 \\
\hline 1 & 13.4 & 8.7 & 7.8 \\
\hline 2 & 11.1 & 8.6 & 7.4 \\
\hline 3 & 8.0 & 7.8 & 8.3 \\
\hline 4 & 8.8 & $13.0^{*}$ & $12.6^{*}$ \\
\hline 5 & 7.7 & $13.6^{*}$ & $12.1^{*}$ \\
\hline \multicolumn{4}{|l|}{ Ludox PT-40 } \\
\hline 0 & 16.3 & 15.0 & 14.7 \\
\hline 1 & 9.7 & 7.4 & 9.1 \\
\hline 2 & 9.6 & 7.8 & 8.9 \\
\hline 3 & 9.6 & 8.9 & 9.0 \\
\hline 4 & 9.0 & $14.4^{*}$ & 9.1 \\
\hline 5 & 9.0 & $12.8^{*}$ & $11.2^{*}$ \\
\hline \multicolumn{4}{|l|}{ Ludox PT40AS-30 } \\
\hline 0 & 16.3 & 15.0 & 14.7 \\
\hline 1 & $9-2$ & 7.4 & 8.9 \\
\hline 2 & 9.0 & 7.7 & 8.7 \\
\hline 3 & 8.9 & 8.7 & 7.7 \\
\hline 4 & 8.8 & $11.7^{*}$ & 9.8 \\
\hline 5 & 8.6 & $10.6^{*}$ & $10.9^{*}$ \\
\hline \multicolumn{4}{|l|}{ Ludox PW-50 } \\
\hline 0 & 16.3 & 15.0 & 14.7 \\
\hline 1 & 10.5 & 8.4 & 7.5 \\
\hline 2 & 9.8 & 9.3 & 9.0 \\
\hline 3 & 9.8 & $10.5^{*}$ & 8.4 \\
\hline 4 & 9.6 & $13.8^{*}$ & 8.3 \\
\hline 5 & 9.0 & $13.2^{*}$ & 8.2 \\
\hline
\end{tabular}

${ }^{*} \mathrm{cf}$ - (cohesive failure of PSA) - samples that leave adhesive residue on both the polyester film banking and the test substrate, in this case steel. ${ }^{* *}$ pcf - (partially cohesive failure of PSA) - adhesive splits between the face stock and the substrate. This result is a direct consequence of an imbalance between cohesive and adhesive properties and is an adhesive weakness. 


\section{Peel adhesion}

In the next part of this work the results concerning the influence of tested silica nanoparticles on the peel adhesion of water-borne acrylic PSA containing above mentioned inorganic nanofillers are presented (Fig. 5).

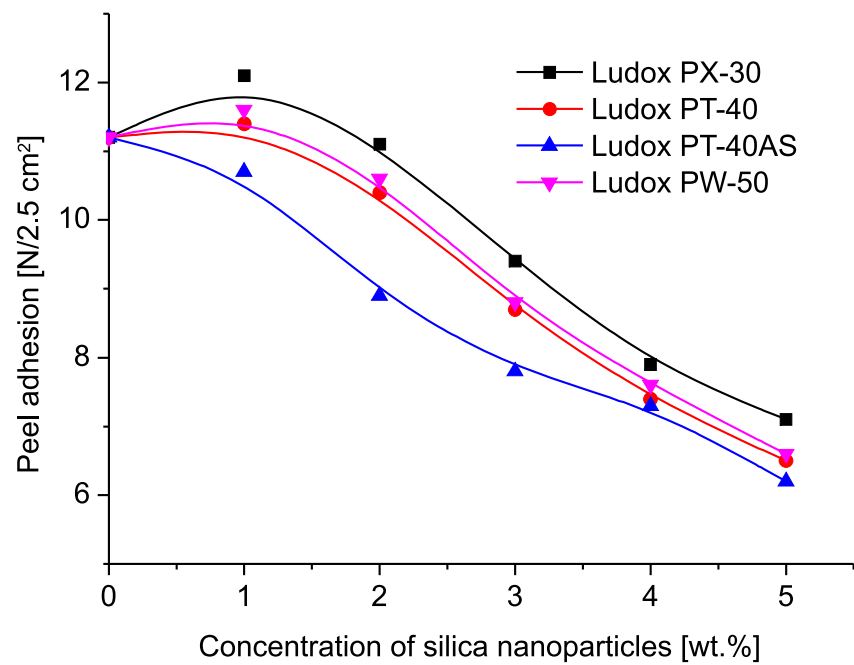

Figure 5. Peel adhesion of water-borne acrylic PSA Acronal 052 modified with silica nanoparticles

The small concentration for example for $1 \mathrm{wt} . \%$ of amorphous silica can activated the acrylic polymeric chain and broaden a better affinity to substrate steel surface. More amount of silica nanoparticles in adhesive layer can migrates on its surface and makes it gradually non tacky what reduces the active contact between adhesive surface and bonding substrate and the peel adhesion dropped.

\section{Shear strength}

On the contrary, to previous cases, an increase of inorganic nanofillers influences shear strength positively. In contrast to the adhesive properties (tack, peel adhesion) the shear strength level attains relatively high values (Fig. 6).

Figure 6 is a graph illustrating the relationship between varying concentration of synthesized amorphous silica nanoparticles and the shear strength of by the use of silica fillers modified commercial water-borne PSA Acronal 052. It should be noted that an almost linear correlation exists between the cohesion values experimentally obtained and the silica nanoparticles content. The highest shear strength value for Acronal

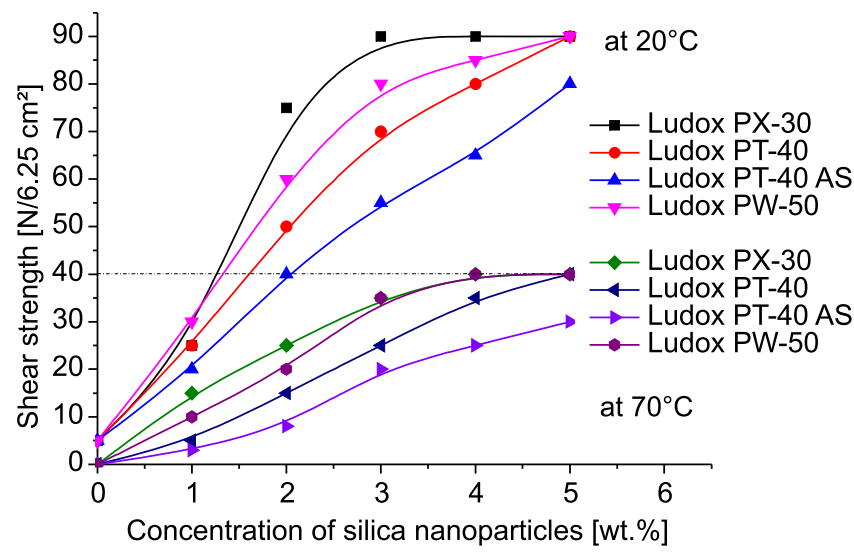

Figure 6. Shear strength of water-borne acrylic PSA Acronal 052 modified with silica nanoparticles
052 modified with four different silica nanoparticles was indicated using amorphous silica Ludox PX-30 what is dependence on stabilizing counter ion sodium in combination with relatively high specific surface area and relatively high alkalinity of this kind of silica. The lowest shear strength was observed by application of amorphous silica Ludox PT-40 AS characterized by relatively specific surface area and containing as stabilizing counter ion ammonium which cannot so good reacted with carboxylic groups from acrylic and methacrylic acid as silica filler stabilizing with counter ion sodium. Addition of all investigated silica nanoparticles probably through reaction between carboxylic groups of polymer and stabilizing counter ion of silica surface provides for the increasing of shear strength.

\section{Removability}

The concentration of the inorganic fillers amorphous silica nanoparticles determines the tack, peel adhesion and shear strength of the investigated water-borne acrylic PSA. For further tests, to investigate the effect of silica nonoparticles on removability of modified aqueous acrylic PSA, were selected Acronal 052 modified with 1, 2 and 3 wt.\% of synthesized amorphous silica Ludox PX-30. The removability results tested as peel adhesion of 45 $\mathrm{g} / \mathrm{cm}^{2}$ thick self-adhesive layers on steel and glass after storage of 3 months at $20^{\circ} \mathrm{C}$ was presented in Figure 7.

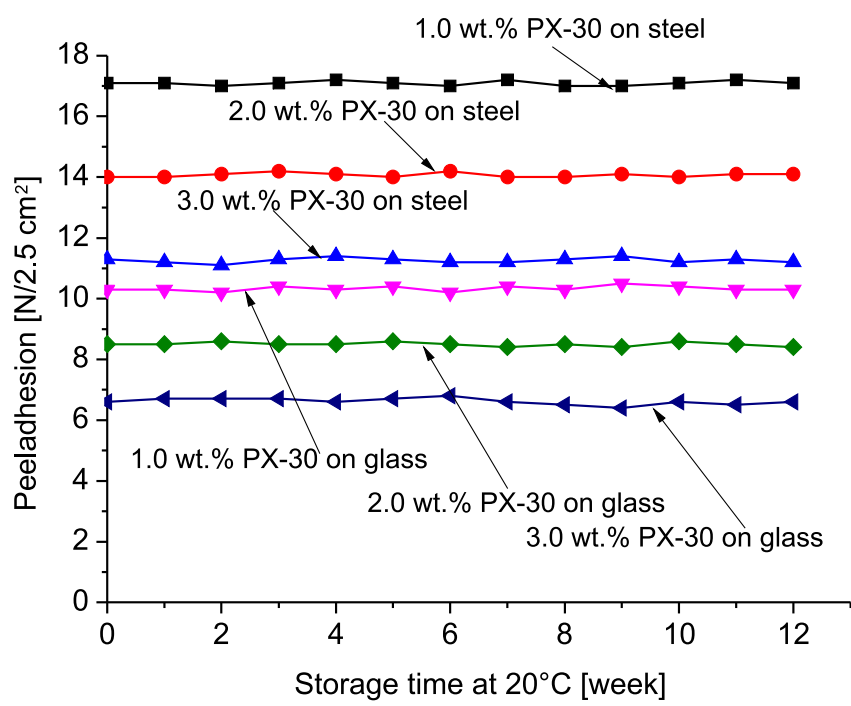

Figure 7. Peel adhesion of water-borne acrylic PSA Acronal 052 modified with silica nanoparticles as a function of storage time

The peel adhesion level evaluated as a removability at room temperature on steel and glass after 1-12 weeks was investigated as well. In terms of the observed peel adhesion values after mentioned period times, the excellent constant removability of water-borne acrylic dispersion Acronal 052 containing 1, 2 and 3 wt.\% amorphous silica nanoparticles on steel and glass. By the same conditions was evaluated the removability of pure Acronal 052 without silica nanoparticles. An increasing of peel adhesion from $17 \mathrm{~N} / 2.5 \mathrm{~cm}$ to $22.3 \mathrm{~N} / 2.5 \mathrm{~cm}$ was observed. 


\section{CONCLUSION}

Nanotechnologically-reinforced systems consisting of monodisperse non-agglomerated silica nanoparticles and water-borne acrylic self-adhesives showed a great enhancement in tack, peel adhesion, shear strength and removability, without showing the disadvantages known to result from the use of other inorganic additives. The scientific literature devoted to nanocomposites, to adhesives and pressure-sensitive adhesives containing nanofillers is both immense and growing. In this study the we have limited our investigation to an aspect of amorphous silica nanoparticles research that we believe deserves more attention by the performance of water-borne acrylic PSA filled with this kind on nanoparticles, especially by shear strength and removability of manufactured self-adhesive materials.

Application of amorphous silica nanoparticles in water-borne acrylic PSA reduced their tack, peel adhesion, can otherwise ameliorated their shear strength and stabilized their removability. In answer to the question, how are suitable investigated amorphous silica nanoparticles for the removable PSA based on water-borne acrylics, the answer is: this kind of nanosilica can be successfully used the manufacturing of high performance removable acrylic pressure-sensitive adhesives. A key property of this type of removable solvent-based acrylic PSA is the adhesion peel does not build with time. Using inorganic amorphous silica nanoparticles, we have also shown that the peel adhesion of coated samples does not build significantly during the aging time. From all tested aqueous silica nanoparticles the best results by application of Ludox PX-30 are noticed. It can be probably attribute to the specific surface area of Ludox PX-30 (215-305 m²/g). Similar values of specific surface area for other silica fillers attain $60-180 \mathrm{~m}^{2} / \mathrm{g}$. Removable and repositionable pressure-sensitive adhesives based on water-borne acrylics will play a major role in the development and production of new generation of removable memo notes, paper and foil labels, double-sided tapes, carrier-free tapes, sign and marking films and protective films.
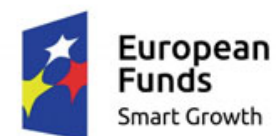

\section{European Union \\ European Regional Development Fund}

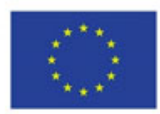

Project entitled: "Development of innovative adhesive containing nanocomponents for the improvement of self-adhesive products", co-funded by the European Union from the European Regional Development Fund.

\section{LITERATURE CITED}

1. Czech, Z. (1999). Crosslinking of pressure-sensitive adhesives based on acrylics, Ed. Szczecin University of Technology, Szczecin, ISBN 83-87423-18-1.

2. Zosel, A. (1985) Adhesion and Tack of Polymers: Influence of Mechanical Properties and Surface Tensions. Coll. \& Pol. Sci. 263(7), 541-553. DOI: 10.1007/BF01421887.

3. Czech, Z. \& Wesolowska, M. (2007). Development of solvent-free acrylic pressure-sensitive adhesives. Eur. Pol. J. 43, 3604-3612. DOI: 10.1016/j.eurpolymj.2007.05.003.
4. Czech, Z. (2003). Crosslinking of pressure-sensitive adhesives based on water-borne acrylates. Pol. Int. 52, 347-357. DOI: 10.1002/pi.1151.

5. Nakayama, Y. (1998). Polymer blend systems for water-borne paints. Prog. Org. Coat. 33, 108-116. DOI: 10.1016/ S0300-9440(98)00021-6.

6. Frisch, F. (2003). Nanotechnology gives a boost to adhesive technology. Adhäsion 4, 16-19.

7. Krüger, G. (2006) Nanoparticles of $\mathrm{SiO}_{2}, \mathrm{ZrO}_{2}$ and $\mathrm{BaSO}_{4}$ in Acrylate Dispersions. Coating 3, 113-115.

8. Sprenger, S., Eger, C., Kinloch, A. \& Ambrose, C. (2004). Nanoadhesives: toughness and high strength, Adh. Adh. \& Seal 3, 20-24.

9. Imerito, T. (2005). Nanotechnology building from the bottom and building the bottom line. JOM 57(12), 18-23. DOI: 10.1007/s11837-005-0177-z.

10. Hertel, T. (2004). Kohlenstoff-Nanoröhren: Bausteine der Mikroelektronik von Morgen. Nach. Chem. 52, 137-140.

11. Liu, J., Fu, S., Yuan, B. \& Deng, Z. (2010). Toward a Universal „Adhesive Nanosheet“ for the Assembly of Multiple Nanoparticles Based on a Protein-Inducted Reduction/Decoration of Graphene Oxide. J. Amer. Chem. Sci. 132, 7279-7281, DOI: $10.1021 /$ ja100938r.

12. Lopez, A., Canetta, L., Creton, C. \& Keddie, J. (2011) Waterborne Polyurethane-Acrylic Hybrid Nanoparticles by Miniemulsion Polymerisation: Applications in Pressure-Sensitive Adhesives. Langmuir 27, 3878-3888. DOI: 10.1021/la104830u.

13. Czech, Z., Arabczyk, W., Hełminiak, A. \& Kowalczyk, A. (2013). Influence of iron carbide filler in carbon matrix on the tack, peel adhesion, shear strength of acrylic pressure-sensitive adhesives. Int. J. Adh. Adh. 40, 210-214.

14. Wady, A.F., Machado, A.L., Zucolotto, V. \& Zamperini, C.A. (2012). Evaluation of Canadia albicans adhesion and biofilm formation on a denture base acrylic resin containing silver nanoparticles. J. App. Micro. 112, 1163-1172. DOI: 10.1111/j.1365-2672.2012.05293.x.

15. Li, M., Daniels, E., Dimonie, V., Sudol, E. \& El-Aasser, S. (2005). Preparation of Polyurethane/Acrylic Hybrid Nanoparticles via a Miniemulsion Polymerization Process. Macromol 38, 4183-4192. DOI: 10.1021/ma048141z.

16. Gashti, M.P., Ali \& Shamei, F.A. (2012). Preparation of water-repellent cellulose fibers using a polycarboxylic acid/ hydrophobic silica nonocomposite coating. Surf. Coat. Tech. 206, 3208-3215. DOI: 10.1016/j.surfcoat.2012.01.006.

17. Amerio, E., Fabbri, P., Malucelli, G., Messori, M., Sangermano, M. \& Taurino, R. (2008). Scratch resistance of nano-silica reinforced acrylic coatings. Prog. Org. Coat. 62, 129-133. DOI: 10.1016/j.progcoat.2007.10.003.

18. Czech, Z. Kowalczyk, A. \& Ortyl, J. 2013. Acrylic pressure-sensitive adhesives containing $\mathrm{SiO}_{2}$ nanoparticles. Pol. J. Chem. Tech. 15(1), 12-14. DOI: 10.2478/pjct-2013-0003. 